\title{
La Plaza de Armas de Cuzco': historias míticas de nacimiento y destrucción
}

\author{
Patricia LUCAS AlONSO \\ Consejo Superior de Investigaciones Científicas (CSIC) \\ patricialucasalonso@gmail.com
}

Recibido: 4/11/2012

Aceptado: 19/11/2012

\section{Resumen}

La Plaza de Armas de Cuzco es uno de los espacios públicos peruanos que condensa una mayor significación mítica. A diferencia de Lima, ciudad de origen colonial, Cuzco era la capital del imperio inca a la que se asociaban diferentes mitos fundacionales. La llegada de los conquistadores supuso, entre otras cosas, una drástica superposición de tradiciones culturales. La plaza se convierte en escenario de sucesos de gran violencia, como la ejecución de Túpac Amaru II. Los mitos de nacimiento se acompañan ahora de relatos de destrucción y muerte que generan estrategias de resistencia. El artículo se propone repasar someramente algunas narraciones asociadas a este espacio, desde las que aparecen en los Comentarios reales a las que forman parte de una rica cultura popular. Se plantea así la posible consideración de esta plaza como un enclave mítico, en el que de manera circular se enlazan relatos de nacimiento, destrucción y renacimiento.

Palabras clave: Perú, Cuzco, Plaza de Armas, Inca Garcilaso, Túpac Amaru.

Title: Cuzco Main Square: Founding Myths and Stories of Destruction

\section{Abstract}

Cuzco Main Square is one of the public spaces in Peru with more mythic significance. Lima was founded in colonial times, but Cuzco was the capital of the Inca Empire and was related to several founding myths. Spanish conquest and colonization created a radical cultural mix. In those times, the square becomes the scene of events of great violence as the execution of Tupac Amaru II. Myths of birth were then joined to stories of destruction and death. Local population created then new resistance strategies. This paper aims to review briefly some stories related to this space. Some of them were registered in ancient chronicles, for instance in Comentarios reales, and others are now part of a rich folk culture. Stories of birth and death are connected to this square. Maybe, it is possible to think in it as an urban myth.

${ }^{1}$ Siguiendo la tradición peninsular he mantenido la grafía Cuzco en la elaboración del texto. Sin embargo, es necesario señalar que la municipalidad del lugar, así como las diferentes instituciones oficiales peruanas, suelen preferir la opción Cusco. Las diferentes grafías, presentes ya desde los primeros registros escritos, responden al estado de las sibilantes castellanas en la época en que los conquistadores llegaron a la ciudad y transcribieron el nombre quechua de la misma. 
Keywords: Peru, Cuzco, Main Square, Inca Garcilaso, Tupac Amaru.

\section{Índice}

1. Las plazas de las ciudades coloniales hispanoamericanas

2. Mitos fundacionales sobre Cuzco

3. Superposiciones violentas

4. Signos de muerte y espacios de resistencia

5. Literatura, cultura popular y finalmente ¿un mito urbano?

\section{Las plazas de las ciudades coloniales hispanoamericanas}

En la retícula de las ciudades coloniales hispanoamericanas, la Plaza de Armas ocupa un lugar protagonista. Se trata del principal espacio público y de representación de los poderes oficiales, tanto civiles como eclesiásticos. En ella aparecen como elementos fijos la catedral y las distintas dependencias de gobierno.

La plaza de Armas de Cuzco no es la excepción, en ella se dan cita importantes monumentos coloniales como la Iglesia de la Compañía de Jesús o la Catedral. En distintas ciudades peruanas es posible encontrar este tipo de espacios rectangulares organizados con esquemas semejantes.

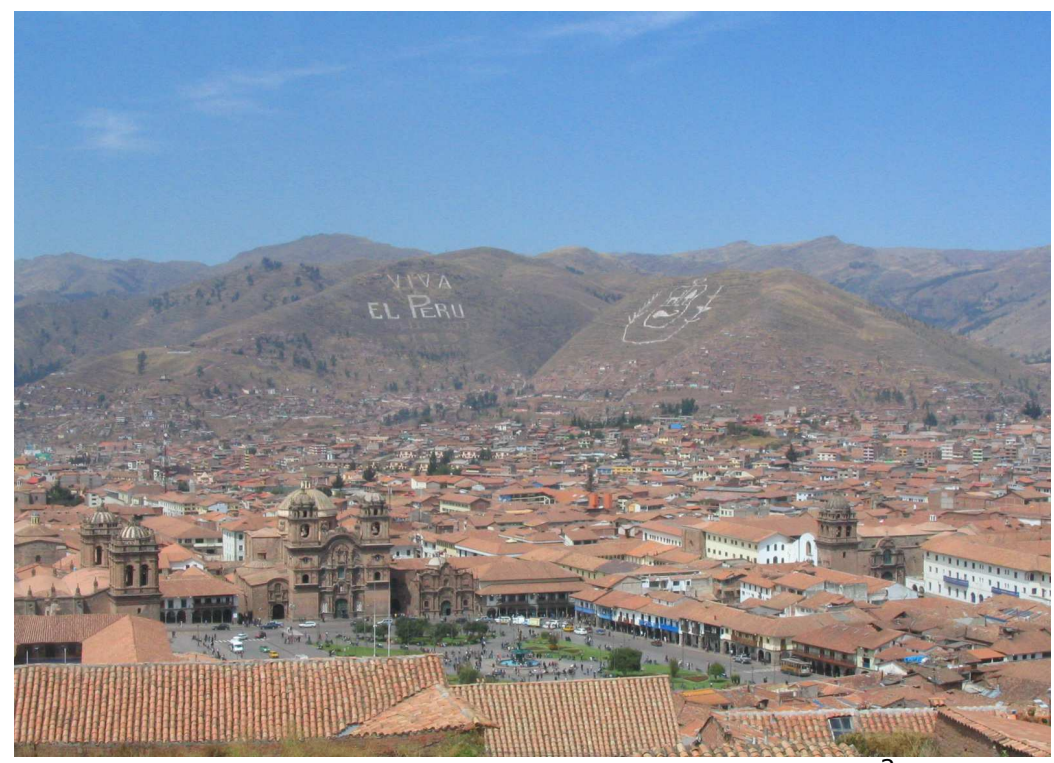

Figura 1. La plaza de Armas de Cuzco².

Existe, sin embargo, una diferencia importante entre el caso cuzqueño y el de otras ciudades de nueva planta. El esquema reticular y los edificios representativos se asientan, en este caso, sobre una ciudad que ya era la capital del imperio incaico. Esto provocará, inevitablemente, una superposición de elementos simbólicos y míticos.

2 Mientras no se indique lo contrario, todas las fotografías son de la autora del artículo. 

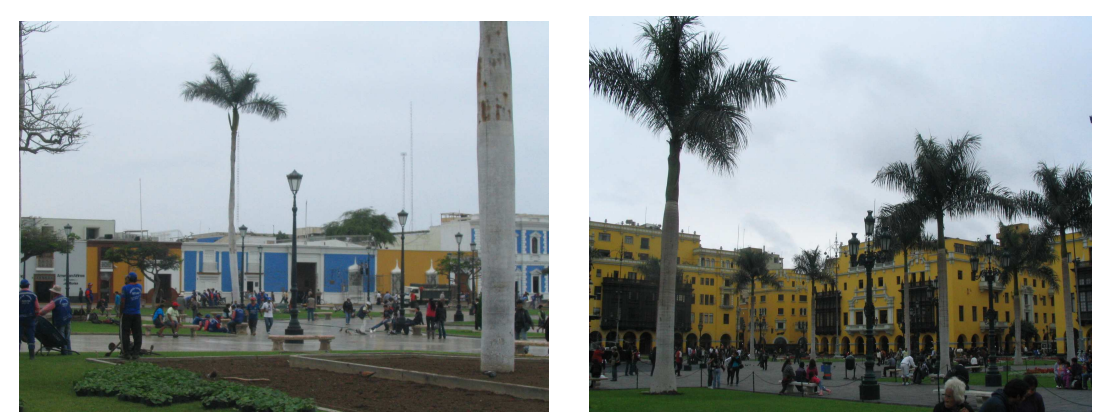

Figuras 2 y 3 . Plazas de Armas de Lima y Trujillo.

\section{Mitos fundacionales sobre Cuzco}

Como sucede en las culturas de la Antigüedad, existen distintas leyendas en el mundo inca que dan cuenta del origen mítico de la ciudad. En el caso de Cuzco, hay dos narraciones asociadas a la fundación urbana, se trata de la historia de los hermanos Ayar y el relato del viaje de Manco Cápac y Mama Ocllo.

La primera de ellas relata el viaje de cuatro hermanos y sus esposas en busca de un valle fértil para fundar una civilización. Distintos avatares hacen que tras el periplo solo persista en la aventura uno de ellos, Ayar Manco, fundador del Cuzco. Se trata del mismo protagonista que aparece en otra de las narraciones sobre el origen de los incas. Es el relato quizá más conocido: la leyenda de Manco Cápac y Mama Ocllo. El Inca Garcilaso 3 recoge esta narración en los Comentarios reales de 1609.

[...] puso nuestro padre el Sol estos dos hijos suyos en la laguna Titicaca, que está ochenta leguas de aquí, y les dijo que fuesen por do quisiesen $y$, doquiera que parasen a comer o a dormir, procurasen hincar en el suelo una varilla de oro de media vara en largo y dos dedos en grueso que les dio para señal y muestra que, donde aquella barra se les hundiese de un solo golpe que con ella diesen en tierra, allí quería el Sol Nuestro Padre que parasen e hiciesen su asiento y corte (Ib. I, XV). (Garcilaso de la Vega 1991: 38)

Los personajes principales de esta historia son la pareja fundacional, descendientes ambos del dios Sol, Inti y de la diosa Luna, Quilla. Desde su lugar de origen, el lago Titicaca, realizan un viaje en busca del lugar indicado para crear una ciudad. La señal que

3 El Inca Garcilaso de la Vega fue un escritor e historiador nacido en Cuzco en 1539, hijo de un capitán español y una princesa inca. Su obra más destacada son los Comentarios reales de los incas, cuya primera parte, publicada en 1609 se centra en la historia y modo de vida del imperio prehispánico. La segunda parte, publicada en 1617 y titulada Historia general del Perú, se centra en la conquista española y el inicio de la colonia. Desde 1560 residió en España, desde allí llevó a cabo la enorme tarea de recopilación de testimonios y memorias que informarán los Comentarios reales. 
les indicará que se encuentran en el lugar preciso será un bastón, que solo se hundirá en el terreno fértil que marca el lugar preciso para la fundación de la ciudad.

Cuzco se convirtió así, según la leyenda, en el origen y la capital del Tahuantinsuyo, es decir del incanato. El propio nombre quechua del territorio ya hace referencia a las cuatro regiones 0 territorios que integraban este imperio que, con centro en el actual Perú, se extendía desde el sur de Colombia al norte de Chile. A fecha de hoy, en la plaza de Armas de Cuzco se recuerda la posición central que la ciudad tenía en este territorio dividido en cuatro grandes regiones: Chinchaysuyo, Antisuyo, Qollasuyo y Kuntisuyo (figura 4).

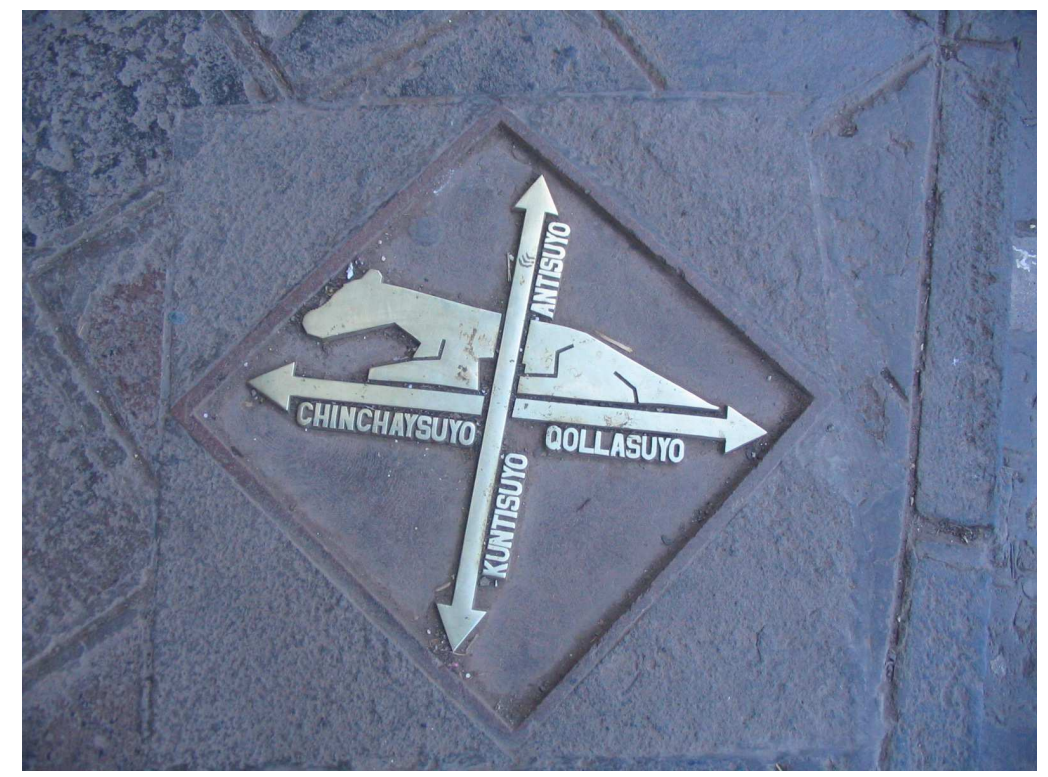

Figura 4. Las cuatro regiones del Tahuantinsuyo.

El carácter fundacional y la centralidad política de la ciudad quedan reflejados en diversas construcciones míticas. En los Comentarios reales del Inca Garcilaso, se alude a la idea de Cuzco como ombligo y centro a partir del cual se organiza el imperio.

Los reyes incas dividieron su imperio en cuatro partes, que llamaron Tauantinsuyu [...]. Pusieron por punto o centro la ciudad del Cuzco, que en la lengua particular de los Incas quiere decir ombligo de la tierra: Ilamáronla con buena semejanza ombligo, porque todo el Perú es largo y angosto como un cuerpo humano, y aquella ciudad está casi en medio (II-lb. XI). (Garcilaso de la Vega 1991: 83)

La metáfora antropomórfica se relaciona a su vez con el mito del Ónfalos de Delfos y apunta hacia el sincretismo cultural del que en buena medida es muestra la propia figura del autor del texto, hijo del capitán español Sebastián Garcilaso de la Vega y de la ñusta o princesa inca Isable Chimpu Ocllo. 


\section{Superposiciones violentas}

La llegada de los conquistadores a Cuzco supone un importante choque cultural del que la ciudad es buena muestra en su propia arquitectura. Los Comentarios reales recogen el cambio que se produce cuando las nuevas autoridades ocupan y transforman lo que hasta ese momento habían sido las residencias del grupo dirigente inca. Sobre los antiguos palacios se sitúan ahora casonas coloniales, templos y capillas. Es el propio padre del Inca Garcilaso, el capitán Sebastián Garcilaso de la Vega, el que autoriza la construcción de casonas en el interior de la plaza. El antiguo espacio libre, de mayor tamaño que el actual, queda segregado en dos ámbitos, el de la actual Plaza de Armas y el de la Plaza Regocijo.

La violenta superposición entre estos dos mundos culturales es visible todavía hoy en la arquitectura de la ciudad. Son muchas las edificaciones en los alrededores de la plaza en las que se advierte cómo sobre el magnífico trabajo de cantería incaica se construyeron residencias o casonas coloniales.

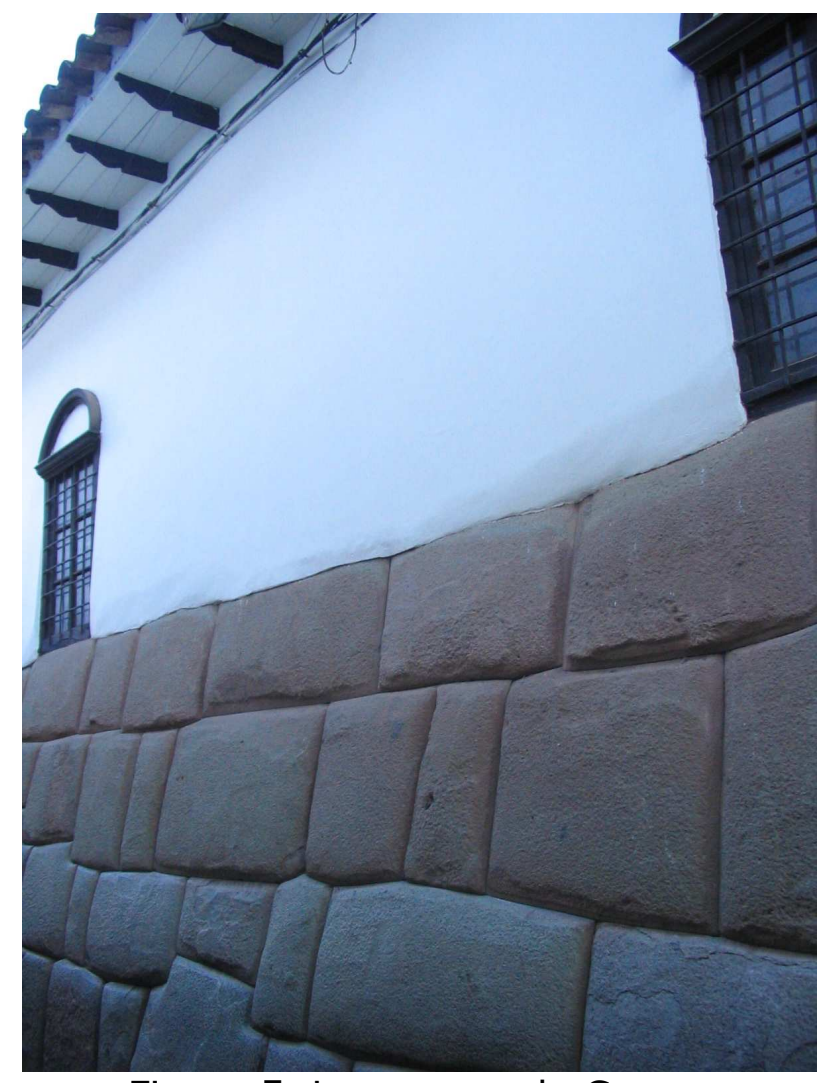

Figura 5. Los muros de Cuzco.

El Inca Garcilaso explica cómo sus antepasados eran capaces de generar interesantes construcciones, puentes, acequias o fortalezas, a pesar de no utilizar el arco o la bóveda. Para apoyar sus palabras emplea numerosos testimonios ajenos, citando a otros cronistas, esta vez de origen peninsular como el Padre Acosta, Pedro de Cieza o al 
Padre Valera: "porque no digan que finjo fábulas en favor de la patria y de los parientes" (lb.V).

El valor de la cultura inca, de sus construcciones y testimonios, es lo que le lleva a expresar el pesar que en él produce el trato lamentable que los españoles han dado a sus edificaciones, de las que no dudan en sustraer piedras para sus propias obras. Llevado de los sentimientos que en él producen sus propias condiciones biográficas, el Inca desarrolla aquí una singular conciencia arqueológica, una visión de la historia y sus testimonios materiales en la que es patente el interés por la conservación del patrimonio.

El Inca se muestra interesado por los logros materiales, constructivos y urbanos de sus antepasados, de ahí su interés descriptivo en la ciudad de Cuzco, construida a imagen del imperio. Una ciudad grandiosa en su pasado indígena, pero que él conoce personalmente cuando ya está inevitablemente tocada por la cultura hispánica. El mestizaje que se ha producido, y del que su propia biografía es un ejemplo evidente, se muestra también en el espacio urbano; de ahí que el Cuzco que nos describe el Inca Garcilaso, el que él vio con sus propios ojos, sea tan mestizo como él mismo. En él se superponen los restos del pasado inca con la inacabable lista de conquistadores y hombres ilustres españoles que han tomado posesión de la ciudad y sus casas.

El espacio urbano del Cuzco se va cargando así de nuevos significados, lo que antes era un lugar fundacional y originario, se convierte en escenario de choques, superposiciones y sucesos violentos ligados a la conquista. Las ideas de nacimiento y destrucción empiezan a convivir en un mismo lugar. Las imágenes de la Nueva crónica y buen gobierno de Guamán Poma ${ }^{4}$ dan buena muestra de ello. La disposición de las figuras y su tamaño relativo ya nos advierten en muchas de las ilustraciones de esa superposición desigual que se está produciendo entre los dos mundos culturales. Cuzco, la antigua ciudad originaria, se convierte en 1572 en el lugar del ajusticiamiento de Túpac Amaru I, el cuarto inca de Vilcabamba ${ }^{5}$.

\footnotetext{
${ }^{4}$ Felipe Guamán Poma de Ayala fue un cronista indígena del Virreinato del Perú. Conocía el quechua, el español y el latín, lo que le llevó a trabajar como traductor para diversos funcionarios coloniales. Alrededor de 1615 dirige un escrito en forma epistolar a Felipe III, exponiéndole la situación de los territorios americanos, se trata de El primer nueva crónica y buen gobierno. El documento, además de testimonios escritos, cuenta con una serie de valiosas ilustraciones que recogen la penosa situación de la población local y a la vez ofrecen una importante muestra de usos y tradiciones.

5 Se conoce como incas de Vilcabamba a los cuatro sucesores de Atahualpa que, entre 1537 y 1572, se enfrentaron a los conquistadores españoles creando un núcleo de resistencia en la zona que hoy se corresponde con el departamento Cuzco. La muerte del último de ellos, Túpac Amaru I, pone fin oficialmente a la conquista del Perú.
} 
El lugar del suceso y el nombre del líder inca pasarán a formar parte de la memoria colectiva indígena, que hará de ellos símbolos de resistencia.

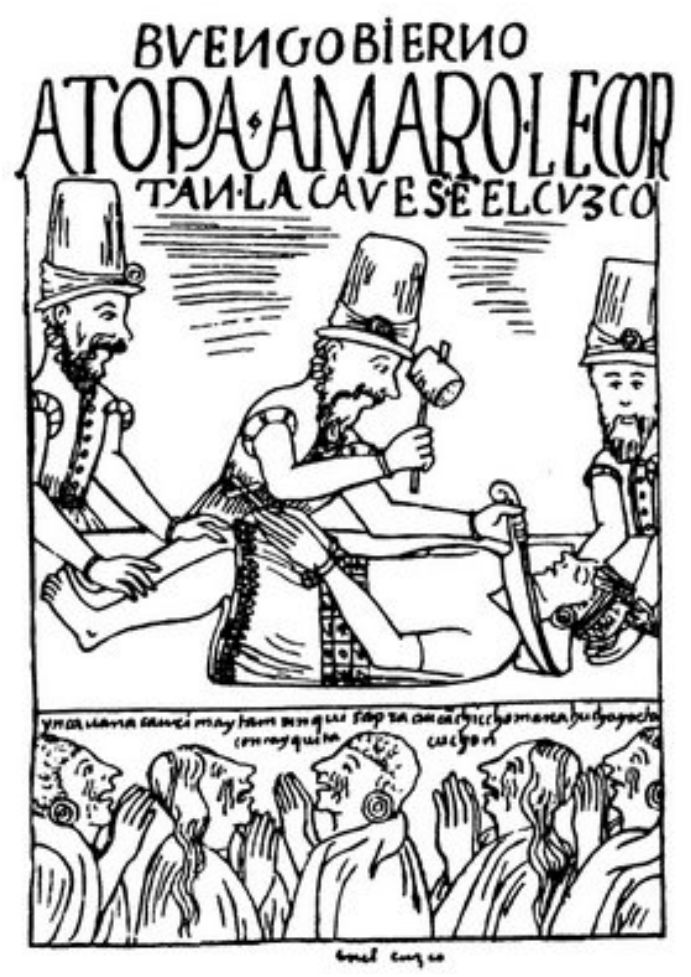

Fuente: Det Kongelige Bibliotek

Figura 6. Imagen de Nueva crónica y buen gobierno de Guamán Poma.

\section{Signos de muerte y espacios de resistencia}

El nombre de Túpac Amaru salta en el tiempo y reaparece en el siglo XVIII. José Gabriel Condorcanqui, descendiente del último inca de Vilcabamba, encabeza la principal revolución indígena y anticolonial que se dio en el continente en aquella época. La sublevación es reprimida violentamente y termina con el juicio y ejecución de Túpac Amaru II en la plaza de Armas de Cuzco, el 18 de mayo de 1781.

La sentencia le obliga a presenciar la tortura y ejecución de sus amigos, aliados, sus hijos y su esposa Micaela Bastidas. Posteriormente intentan descuartizarlo atando su cuerpo a cuatro caballos. Finalmente es decapitado y diversas partes de su cuerpo son expuestas en diferentes lugares del virreinato. La plaza de Armas de Cuzco, que antes había sido origen y ombligo del imperio inca, se convierte ahora en escenario de violencia y símbolo de resistencia, pero también en foco a partir del cual se expande la historia de Túpac Amaru. El lugar sigue operando como punto centrífugo a partir del cual se articulan relatos e identidades. La ciudad mítica, origen del 
mundo inca, es ahora el lugar del que parte un testimonio de resistencia. La rebelión se convierte en un motivo de identidad cultural (Stavig 1999).

Por motivos obvios, la historia se difunde de manera soterrada, quizá una de las estrategias más singulares para lograrlo fue el relato gráfico del mito. El tejido y sus simbologías, especialmente importantes en el mundo andino, acogen la figura de Túpac Amaru II y cuentan a través de imágenes su historia de rebelión y su final en la plaza del Cuzco. El tejido se constituye así en un medio de preservación de la memoria y transmisión del relato al margen de los cauces letrados oficiales.

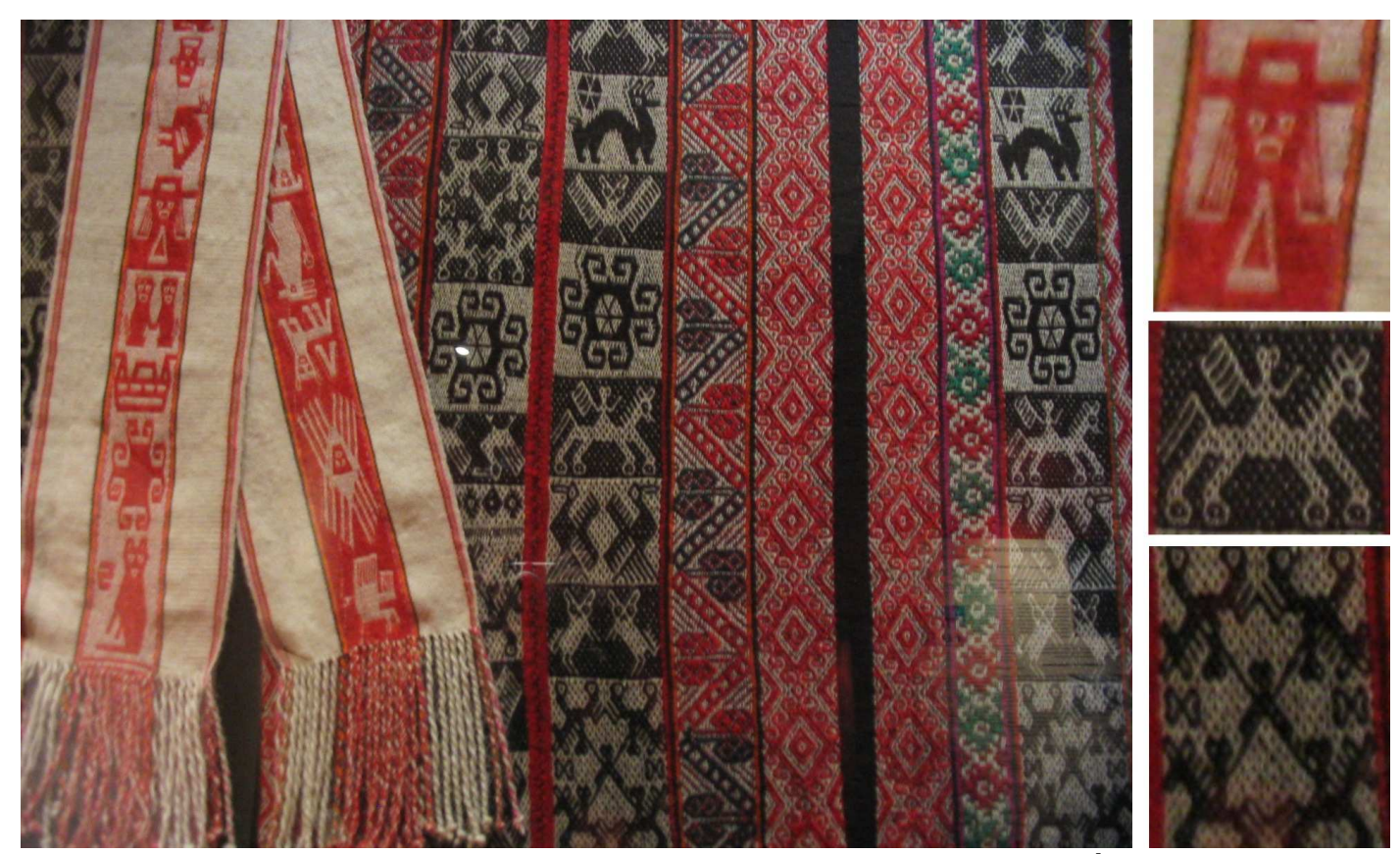

Figura 7. Tejidos con mensajes de resistencia (Museo Histórico Regional del Cusco - Casa natal Inca Garcilaso de la Vega).

\section{Literatura, cultura popular y finalmente ¿un mito urbano?}

Lo acaecido en la plaza de Cuzco y la historia de Túpac Amaru pasó a formar parte de una cultura popular de resistencia que poco a poco fue exteriorizándose. Así en marzo de 1781 se fijó un bando en la puerta de la Audiencia de Charcas que hacía alusión a estos sucesos (Poderti 1997: 57).

Nuestro Gabriel Inca vive jurémosle pues por Rey porque viene a ser en ley y lo que es suyo reciba. [...] morirán como el soldado, alcaldes, corregidores, ricos, pobres y oidores o no he ser Túpac Amaru 


\section{$[\ldots]$ \\ Oir, tributos doblados \\ ver los repartos ingentes \\ el clamor de tantas gentes \\ están los pueblos turbados; \\ desde el Cuzco aligados \\ advertir podéis vosotros \\ si de Lupa y estos otros \\ quieres los muertos vengar \\ que no han de resucitar \\ muriendo todos nosotros.}

En la literatura de la época virreinal la historia se recoge en pasquines. En la época republicana, la figura de Túpac Amaru pasará a formar parte del imaginario colectivo peruano. Como líder de la rebelión anticolonialista, se aludirá a él en numerosas composiciones poéticas (Ángeles Caballero 1971). De entre todas ellas, el himnocanción de José María Arguedas, Túpac Amaru Kamaq taytanchisman. Haylli-taki. A nuestro padre creador Túpac Amaru es quizá una de las más conocidas. También en los años sesenta, sale a la luz el Cantar de Túpac Amaru de Manuel Scorza.

Túpac Amaru, hijo del Dios Serpiente, hecho con la nieve del Sinqantay; tu sombra llega al profundo corazón como la sombra del dios montaña, sin cesar y sin límites. (Arguedas 1962)

iHombres de las nieves, hombres de las arenas, hombres del mar! iHoy es el día del canto!

[...]

iEntrad también a la plaza del Canto!

[...]

Y dónde humeó la pelea?

En Huamanga, la Beata?

En Trujillo, la Florida?

En el Cuzco, por sus tesoros famosa? (Scorza 1990)

La dimensión de la figura de Túpac Amaru ha ido en aumento, desbordando el ámbito espacial en el que, con su ejecución, se dio nacimiento al mito. Su nombre ha trascendido el ámbito cuzqueño para unirse a movimientos y asociaciones variadas en toda Latinoamérica. Desde bandas de rock, asociaciones barriales, o el mismo MRTA, muchos y muy distintos son los movimientos que aluden en su denominación a esta figura.

El fenómeno no es exclusivamente peruano, sino que aparece en todo el continente. En las versiones cinematográficas que aluden a la figura de Túpac Amaru, se observa este mismo hecho. Si bien hay películas, como Túpac Amaru (García Hurtado, dir., 1984), que parecen centrarse más en lo biográfico, también existen narraciones 
en las que la alusión a la figura mítica se liga a movimientos sociales o de trabajo solidario. Es el caso de Tupac Amaru. Algo está cambiando (Palumbo y Buj, dirs., 2012), que se desarrolla en la provincia argentina de Jujuy y retrata una historia de organización barrial.

En los mitos fundacionales incaicos, la ciudad de Cuzco actuaba como foco centrífugo. En la historia de Túpac Amaru, la plaza de Armas se ha convertido en el enclave a partir del cual nace un mito cargado de significados de identidad, sociales y reivindicativos. Se trata de una figura que ha pasado a formar parte de los imaginarios populares.

No es difícil encontrar imágenes y alusiones a esta figura mítica en el mundo cultural urbano de los nuevos barrios de ciudades como Lima. La migración campo-ciudad ha dibujado un nuevo panorama generado por el desborde popular (Matos Mar 1987). Estos barrios, los famosos conos de Lima, son el escenario de manifestaciones culturales propias, como la música chicha, o de procesos sociales como la llamada cholificación (Quijano 1980). Se trata de un mundo posmoderno, lejano ya de lo mítico y lo ancestral, pero también ahí es posible encontrar alusiones a la figura de Túpac Amaru y a su ejecución en la plaza del Cuzco. Por ejemplo, el nombre que ha elegido uno de los artistas gráficos más destacados en el mundo del cartel chicha ${ }^{6}$ no es otro que Elliot Tupac.

De lo indígena a lo urbano, de Cuzco a los conos de Lima, en variados entornos y con diferentes expresiones, es posible encontrar alusiones a un conjunto de elementos míticos que conforman una identidad que, en muchos casos, trasciende incluso lo nacional. Cuzco, capital histórica del Perú, fue para los incas el origen y centro del imperio. Su plaza de Armas es buena muestra del choque cultural que supuso la llegada de los conquistadores. El nacimiento y la destrucción se han superpuesto en esta ciudad. Este espacio público ha sido escenario de sucesos que quizá han alcanzado ya el rango de mitos en la cultura popular urbana.

\footnotetext{
${ }^{6}$ Los carteles que anuncian los conciertos de música chicha o cumbia andina han desarrollado un lenguaje plástico propio, basado en el trabajo tipográfico y el empleo de colores fluorescentes. Una buena muestra de este tipo de carteles pudo verse en la exposición Letra capital, que recopilaba el trabajo de Elliot Tupac y que tuvo lugar en la Galería Municipal de Arte Pancho Fierro de Lima, con la curaduría del antropólogo César Ramos, entre el 4 de octubre y el 18 de noviembre de 2012.
} 


\section{Bibliografía}

ÁNGELES CABALLERO, César A. (1971): Poemas a Túpac Amaru. Lima: C. Lanegra.

ARGUEDAS, José María (1962): Túpac Amaru Kamaq taytanchisman. Hayllitaki. A nuestro padre creador Túpac Amaru. Himno-canción. Lima: Salqantay.

GARCILASO DE LA VEGA, Inca (1991): Comentarios reales de los incas. Edición de Aurelio Miró Quesada. Caracas: Biblioteca Ayacucho.

GUAMÁN POMA DE AYALA, Felipe (1980): Nueva crónica y buen gobierno. Caracas: Biblioteca Ayacucho.

MATOS MAR, José (1987): Desborde popular y crisis del estado. El nuevo rostro del Perú en la década de 1980. Lima: Instituto de Estudios Peruanos.

PODERTI, Alicia (1997): Palabra e historia en los Andes. La rebelión del inca Túpac Amaru y el noroeste argentino. Buenos Aires: Corregidor.

QUIJANO, Aníbal (1980): Dominación y cultura. Lo cholo y el conflicto social en el Perú. Lima: Mosca Azul editores.

SCORZA, Manuel (1990): Obras completas, vol. I, obra poética. México: Siglo XXI.

STAVIG, Ward (1999): The world of Túpac Amaru: conflict, community, and identity in colonial Peru. Lincoln: University of Nebraska Press.

\section{Filmografía}

GARCÍA HURTADO, Federico (dir.) (1984): Túpac Amaru. Perú / Cuba: Cinematográfica Kuntur S.A. / ICAIC.

PALUMBO, Federico; y BUJ, Magalí (dirs.) (2012): Túpac Amaru. Algo está cambiando. Argentina: Productora Federico Palumbo \& Magali Buj. 